\title{
A Case Study on Teaching Business Courses in English or Bilingualism with Guangwai as an Example
}

\author{
Wenzhong Zhu ${ }^{1}$, Xuping Deng ${ }^{1} \&$ Jingyi $\mathrm{Li}^{1}$ \\ ${ }^{1}$ School of English for International Business, Guangdong University of Foreign Studies, China \\ Correspondence: Zhu Wenzhong, Professor of School of English for International Business, Guangdong \\ University of Foreign Studies, Guangzhou 510420, China. Tel: 86-20-3620-6599. E-mail: \\ wenzhong8988@sina.com
}

Received: June 20, 2014 Accepted: July 25, 2014 Online Published: August 14, 2014

doi:10.5539/elt.v7n9p156 URL: http://dx.doi.org/10.5539/elt.v7n9p156

\begin{abstract}
Teaching courses in a foreign language was formally promoted by Ministry of Education in China in 2001. Guangdong University of Foreign Studies (Guangwai) as a top 3 Chinese foreign language university has taken the lead in teaching business courses in English instruction or bilingual languages. The paper summarizes and analyzes Guangwai's experiences in implementing this teaching mode, such as the types of courses taught in this mode, the conditions required for teachers, the selection of teaching materials, etc., so as to provide some useful references for the university and other universities.
\end{abstract}

Keywords: business courses, teaching in English or bilingualism, Guangwai's experiences, references

\section{Introduction}

In English immersion classrooms, a teacher who is a non-native English speaker and whose first language is Chinese conducts lessons entirely in English for approximately half the school day. This mode of teaching in China is often named as teaching courses in English, another foreign language or bilingualism.

Teaching courses in English, another foreign language or bilingualism (foreign language and Chinese language) was formally promoted by China Ministry of Education (2001) in the Official Document (2001) No.4 concerning the Education Guidelines of Enhancing College Undergraduate Teaching Work, actively promoting Chinese higher education institutions to realize the three-year target of the teaching of 5-10\% courses in English or other foreign languages, with the purpose of cultivating talents of international competitiveness in face of challenges of higher education modernization and economic globalization as well as technological revolution.

Ever since then, more and more universities in the whole country have experimented the teaching of their specialized courses in English, another foreign language or bilingual languages. This type of teaching innovation or reform has been more successful in those universities in large cities, where more teachers are normally recruited with a foreign education background or awarded with a foreign language degree, especially these universities categorized as foreign language or international trade institutions.

The advantages of teaching courses in English or bilingualism can be seen as the following: such as the higher productivity of learners' education investment, the better improvement of learners' English language proficiency and linguistic abilities, learners' mastering of related disciplinary knowledge, learners' enhanced understanding of other countries' cultures or improvement of cross-cultural communication abilities, learners' increased competitiveness for job opportunities because of their multi-skills in both language and a specific discipline.

At the same time, this mode of teaching has also brought some challenges, doubts and problems in recent years. For example, some educators argue that it is necessary and feasible to conduct the teaching of courses in a foreign language or bilingual languages because students can reduce their costs of education by integrating the learning of a specialized knowledge with the study of a foreign language, and can directly learn the updated international knowledge or skills from the world by being instructed in English or another foreign language; some others argue that it is not feasible at all because students usually have difficulties in learning their degree courses in the local language or Chinese, and it is even impossible for them to learn the courses well in a foreign language.

Guangdong University of Foreign Studies (Guangwai or GDUFS) is a top 3 Chinese university of foreign 
languages. Guangwai is well recognized for its distinctive features of internationalization in South China, and its education of internationally-oriented personnel and its researches on foreign languages \& culture, international trade and international strategic studies. It was created by a merger in 1995 of Guangzhou Institute of Foreign Languages and Guangzhou Institute of Foreign Trade. The University upholds the motto of Pursuit of Integrity, Practice and Cross-cultural Learning and defines as its mission the training of high-caliber global citizens through the integration of content studies and foreign language training for globally minded graduates with international vision and social responsibility.

As a result of these features and advantages, Guangwai has taken the lead in teaching its business courses in English or bilingualism in the whole country. This paper in the following aims to make an analysis of Guangwai's experiences in implementing this teaching mode, such as the courses taught in this mode, the conditions required for teachers, the selection of teaching materials, and the effect of student learning, etc., so as to provide some useful references for other universities.

\section{Literature Review}

\subsection{Definitions and Origins}

Teaching courses in English or bilingualism in China is commonly believed to have originated from the method of language immersion teaching. Language immersion, or simply immersion, is a method of teaching a second language in which the learners' second language (L2) is the medium of classroom instruction. Through this method, learners study school subjects in their L2. The main purpose of this method is to foster bilingualism, in other words, to develop learners' communicative competence or language proficiency in their L2 in addition to their first or native language (L1).

Based on the language immersion from Wikipedia (2013), according to class time spent in a foreign language, language immersion programs can be divided into five types, and each of the programs have a specific goals to be achieved. See Table 1:

Table 1. Types of language immersion program

\begin{tabular}{|c|c|c|}
\hline Type of immersion & $\begin{array}{l}\text { Class time spent in } \\
\text { a foreign language }\end{array}$ & Goals of the immersion program to be achieved \\
\hline $\begin{array}{l}\text { Complete foreign language } \\
\text { immersion }\end{array}$ & Almost $100 \%$ & $\begin{array}{l}\text { To become functionally proficient in the foreign } \\
\text { language, to master subject content taught in the } \\
\text { foreign languages, and to acquire an } \\
\text { understanding of and appreciation for other } \\
\text { cultures. }\end{array}$ \\
\hline $\begin{array}{l}\text { Partial foreign language } \\
\text { immersion }\end{array}$ & About half & $\begin{array}{l}\text { To become functionally proficient in the second } \\
\text { language, to master subject content taught in the } \\
\text { foreign languages, and to acquire an } \\
\text { understanding of and appreciation for other } \\
\text { cultures, but to a lesser extent than complete } \\
\text { immersion }\end{array}$ \\
\hline $\begin{array}{l}\text { Content-based foreign } \\
\text { language immersion }\end{array}$ & About $15-50 \%$ & $\begin{array}{l}\text { To acquire proficiency in listening, speaking, } \\
\text { reading, and writing the foreign language, to use } \\
\text { subject content as a vehicle for acquiring foreign } \\
\text { language skills, and to acquire an understanding } \\
\text { of and appreciation for other cultures }\end{array}$ \\
\hline $\begin{array}{l}\text { Foreign language experience } \\
\text { immersion }\end{array}$ & Less than $15 \%$ & $\begin{array}{l}\text { To acquire proficiency in listening and speaking, } \\
\text { to acquire an understanding of and appreciation } \\
\text { for other cultures, and to acquire some } \\
\text { proficiency in reading and writing }\end{array}$ \\
\hline
\end{tabular}

Notes: Adapted based on the idea of Wikipedia (2013) 
In fact, the first modern language immersion programs appeared in Canada where French-speaking Canadians are many but English is the official language in the 1960s. Middle-income Anglophone (English-speaking) parents there convinced educators to establish an experimental French immersion program enabling their children to appreciate the traditions and culture of French-speaking Canadians as well as English-speaking Canadians (Baker, 1993). Johnson and Swain in 1997, makes a research of the immersion worldwide illustrated by case studies of thirteen programs. They also argue that immersion, a relatively new approach to bilingual education, originated in Canada, which uses the target language as a medium of instruction in order to achieve "additive bilingualism"- a high level of second language proficiency (Johnson \& Swain, 1997).

\subsection{Researches in China}

The first English immersion project in China began in 1997 in Xi'an, which was for teaching English to Chinese-speaking children. This English emersion for Chinese-speaking babies involves the method of second language teaching to allow children to stay in an English language environment in the whole or partial class time, where the teacher teaches courses to them in English, aiming to integrate the learners' learning of language and study of knowledge together, and to increase the motivation and interest of learners.

However, teaching business courses in English or bilingualism to adults in Chinese higher education institutions only dates back to 2001 in China as a result of the promotion role of the Official Document (2001) No.4. And there have been some researchers who have put forward important related research conclusions. Professor Cai Yun in Guangdong University of Foreign Studies argues that teaching business courses in English is a very important and necessary teaching mode of integrating the learning of a specific business knowledge with the learning of English language (Cai, 2001).

In 2003, Dai Xuanyuan makes an analysis of the basic conditions or factors influencing the teaching quality of marketing course in bilingualism based on the case of Beijing Normal University. The basic conditions include the factor of courses, the factor of teachers, the factor of core textbooks, and the factor of students. For example, the paper argues that the courses of mathematics, politics, history and culture, etc., are not necessary to be taught in English or bilingualism, while business, trade and economics courses are feasible to be taught in bilingualism (Dai, 2003).

In 2005, the author makes an empirical analysis of Teaching Courses in English for the students of Business English major based on the case of Guangwai (Guangdong University of Foreign Studies), finding that the concept and mode of teaching business courses in English should be well informed to or discussed with the learners of Business English, the selection of foreign English teaching materials or textbooks should be taught with some Chinese local practices and cases, and the development of multi-skilled teachers should be strengthened, etc. (Zhu, 2005). At the same, there are many other researchers who have made related studies and drawn some findings. For example, Cai yun makes a research on the design and implementation of English immersion education by taking the programme of international business management (taught in English) as an example, and argues that this education mode should be fit for the students' English language proficiency, the teachers of this programme should process both English proficiency and a business disciplinary qualification, and the teaching practices should emphasize on the combination of theories with business practices, etc. (Cai, 2005).

There are some criticisms concerning the teaching of courses in English or bilingualism. Song (2007) makes an analysis of the mode of English immersion education, and argues that English immersion education is becoming popular in the whole country, but not many people show doubts about its problems, shortcomings or disadvantages such as insufficient evaluation system, teaching staff, students and teaching materials, etc. He suggests that measures should be taken to handle these problems to face the challenge of this education mode.

There are also some other researches focusing on the immersion education of other majors or disciplines. For instance, Ouyang (2011) makes a specific research on the teaching strategies for international special talents based on the example of Beijing University of Commerce's CAP education, and argues that the English immersion teaching of CAP students in the university has achieved a great success through the reforms of curriculum design, student selection, and teacher development.

There are also some researches in China who have made some comparative studies on teaching in English or bilingualism. For example, Xiao (2012) conducts a comparative study and analysis of English immersion teaching modes in higher education institutions between Hong Kong and Mainland, and suggests that the universities in the Mainland should learn from Hong Kong in conducting this mode of teaching or education. That is to say, the university should give the right of choosing the English immersion program or not to the students themselves. It is better to classify only the students who have passed a required English proficiency 
level into the classes taught in English or bilingualism. Qiang and Siegel (2012) makes a comparative research and argues that to sustain an effective transplanted English immersion program, necessary modifications must be made to respond to the social and educational contextual restrictions in the "borrower" country.

In addition, Zhou (2013) makes an analysis of the application of the teaching method of case studies in teaching the course of international trade practices in English, and argues that the teaching method of case studies is an effective way in teaching the course of international trade practices in English.

All the above researches and findings, although not directly related to the current case study, have paved a foundation for conducting the case analysis of Guangwai's experiences in implementing the mode of English immersion or teaching business courses in English, covering the research questions such as what are the types of courses taught in this mode? What qualifications are required for the teachers? How to select the teaching materials? etc. The unique case analysis findings will of course enrich the related research scope and provide some useful references for other universities.

\section{Case Analysis}

\subsection{Types of Courses Taught in English or Bilingualism}

It should be first mentioned that teaching courses in English or bilingualism in Chinese universities may be tricky in the definition. Theoretically speaking, teaching courses in English means teaching the courses in 100\% English while teaching courses in bilingualism means teaching the courses in 50\% English and 50\% Chinese. Teaching courses in bilingualism is the preliminary stage of teaching courses in English. Teaching courses in English is considered to be the highest level of teaching courses in bilingualism, because in the practice, teaching the courses in $100 \%$ English is simply not feasible or even unnecessary.

As a whole, Guangwai has about 200 undergraduate courses and about 20 postgraduate business courses taught in English or bilingualism. In the practices of Guangwai, teaching business courses in English or bilingualism can be divided into the three main types based on the nature of degree programs, classes or courses rather than the percentage of the language spent in the class as mentioned in the above paragraph.

First, degree programs taught in English or bilingualism. In Guangwai, the degree programs taught in English include the postgraduate degree program of MBA in English instruction and the undergraduate degree programs of English language, Business English and English education, in which nearly all their non-language modules or business courses are taught in English or bilingualism, only with the modules of mathematics and politics as exceptions.

Second, classes taught in English or bilingualism. In Guangwai, the classes taught in English are actually the business-related majors taught in English, which are normally called Quanyingban (English instruction class) or Chuangxinban (innovation class). These classes include the innovation class of international business offered by School of English for Business, the innovation class of international trade offered by School of International Trade and Economics, and the innovation class of accounting offered by School of Finance, etc. These classes are just a small part of the same business degree program traditionally taught in Chinese, which will be awarded the same business degree certification after graduation, but the only difference is that these innovation classes are taught in English as a kind of innovation. The number of these classes in Guangwai is no more than 10. Almost all the modules of these classes required for the awarding of related degrees are taught in English or bilingualism, only with the modules of mathematics and politics as exceptions.

Third, courses taught in English or bilingualism. In Guangwai, the courses taught in this mode refer to the partial courses of the non-language undergraduate or postgraduate degree programs offered by School of International Trade and Economics, School of Management, School of Finance, School of Law, School of Information, School of Journalism, etc. These courses such as International Trade Simulation, International Financial Management, International Logistics Management, International Investment Law, and Application of Business Statistics Software only take up a certain part of all the modules required for the awarding of a related degree. For example, in School of Management, there are only 6 courses taught in English or bilingualism; in School of Finance, there are only 2 courses taught in this mode; in School of Law, there are also a few courses of Juries Master degree Programs taught in bilingualism. In terms of the courses taught in this mode at the postgraduate level, more details can be seen in the following table: 
Table 2. Postgraduate courses taught in English or bilingualism (not including the courses of MBA)

\begin{tabular}{lll}
\hline School Name & Course Name & Class Type \\
\hline School of International & Cultural Studies on European Integration & Compulsory \\
Trade and Economics & Research Seminar on WTO & Compulsory \\
& Seminar in Input-Output Analysis & Compulsory \\
School of Law & Survey of European Union Law & Compulsory \\
& International Relations Theory & Compulsory \\
& Principles of Political Science & Compulsory \\
& Comparative Law & Compulsory \\
& Regional Economic Law & Compulsory \\
& Foreign Civil and Commercial Law & Compulsory \\
Business Management & Financial Accounting Theory & Compulsory \\
& Econometrics & Compulsory \\
& Financial Management & Selective \\
& Corporate Finance & Selective \\
& Financial Risk Management & Selective \\
& Management Research Methodology & Selective \\
& Human Resource Management & Selective \\
Corporate Strategic Management & Selective \\
Logistics and Supply Chain Management & Selective \\
Research on Organization Behavior & Selective \\
Marketing Management & Selective \\
\hline
\end{tabular}

Notes: Adapted from the announced information of Division of Graduate Education of Guangwai

\subsection{Qualifications Required for Teachers}

Teachers are one of the key factors for the success of teaching business courses in English or bilingualism. Guangwai has established a comparatively good teaching staff able to conduct English immersion teaching in these years through teacher recruitment, training, development and education. These teachers are a little more than 100 in Guangwai, and their qualifications required are seen in the following table:

Table 3. Qualifications for teachers teaching business courses in English or bilingualism

\begin{tabular}{lll}
\hline Series No. & Qualifications required & Suitability Level \\
\hline 1 & $\begin{array}{l}\text { BA degree in English language }+ \text { MA or PhD degree in business } \\
\text { Overseas study or business work experience }\end{array}$ & Best \\
2 & BA degree in English language + MA or PhD degree in business & Excellent \\
3 & BA, MA or PhD in English language + domestic business work experience & Good \\
4 & BA, MA or PhD in English language + self study of business & OK \\
\hline
\end{tabular}

Notes. Degrees in English language include those in Business English

From the above table, regardless of English teaching skill or methodology, we can see that the teachers with qualifications in both English language and business knowledge are normally the most suitable ones for teaching business courses in English or bilingualism. This may not represent all the teachers who can teach these courses with the best performance. In the practice, we do see some teachers who are degree graduates of business major rather than degree graduates of English language, but have very good English proficiency, can also teach the 
courses in English or bilingualism very well. However, in the practice of Guangwai so far, the best performance in this teaching mode mostly belongs to the teachers with BA degree in English language and $\mathrm{MA}$ or PhD degree in business. Business work experiences can also add additional advantages to the teachers.

But in whatever situations, the qualifications had better include both English language and business knowledge for the teachers, and BA degree in English is usually the first most important qualification. The ideal type of these teachers is those who are equally good in both English and business while the second best type should be those who are very good in English but OK in business, or who are OK in English but very good in business. The author has ever made a questionnaire study on the students' expectation that are at schooling in Guangwai about what is the most important qualification for the teachers teaching business courses in English, and finds that over $77 \%$ of them in the survey choose the answer that the teachers should be equally good in English and business (Zhu, 2011).

In addition, the feedbacks from the students concerning the major problem impacting the effect of teaching business courses in English or bilingualism also indicate the importance of teachers' English language proficiency or qualification. One of the most commonly complained or reflected problems by the students as learners about this mode of teaching is the English language problem of their teachers, for example, some students complain that their teachers whose spoken English has not passed the required level, or is unqualified, just teach the courses mostly in Chinese; some others suggest that their teachers who are non-English-language graduates and have no overseas study or work experiences should not teach the courses in English or bilingualism; some others suggest that the teachers who are purely graduates of English language major should improve their business knowledge or ability themselves before teaching these courses, and so on.

\subsection{Choices of Teaching Materials}

In terms of choices for teaching materials for teaching business courses in English or bilingualism in Guangwai, a majority of textbooks used are original English business textbooks imported from foreign countries, and the PPTs of the teaching materials are mostly prepared or presented in English, with only a few key business terms or theories in Chinese. But there is no evidence indicating that the core textbooks used by the teachers teaching business courses in English or bilingualism are purely those written in Chinese.

But the original foreign core textbooks written in English may not be completely adoptable for Chinese students or learners in Chinese environment, so the teachers usually add some complementary teaching materials in Chinese, such as the related business textbooks in Chinese or Chinese business case studies in Chinese, in order to integrate the business theories or practices in the original foreign books with the real business situation of China.

There are also some teachers in Guangwai, who compile and use their own core text books in English or use the textbooks compiled in English by other Chinese scholars. But the teachers' self-written textbooks are not very much welcome by the students in the practice, who tend to believe that the English language expression in the self-written textbooks is not as simon-pure as that in the foreign original ones.

Based on the author's questionnaire survey, the above ideas about choices of teaching materials have been verified (Zhu, 2011). Table 4 shows that over 62 percent of the investigated students recognize the mixed use of original foreign core textbooks written in English and some supplementary domestic teaching materials written in Chinese; 38 percent of the students agree with the single use of original foreign core textbooks written in English so that they can learn standard English and international business knowledge keeping in line with the modern world society. However, there are no students who have chosen the answer of purely using the textbooks written by Chinese scholars in English.

Table 4. Expectations of the investigated students about the use of teaching materials

\begin{tabular}{lll}
\hline Teaching materials & Students investigated & Agreement \% \\
\hline $\begin{array}{l}\text { Mixed use of Original core textbooks in English } \\
\text { supplementary domestic teaching materials in Chinese }\end{array}$ & $\begin{array}{l}\text { Foreign trade major and international } \\
\text { finance major at three grades }\end{array}$ & $62 \%$ \\
$\begin{array}{l}\text { Complete use of original core textbooks in English } \\
\text { Pure use of the textbooks written by Chinese scholars }\end{array}$ & The same as above & $38 \%$ \\
in English & & $0 \%$ \\
\hline
\end{tabular}

Notes. Adapted from Page 117 of Business English Teaching and Research, 2011 


\subsection{Problems of This Teaching Mode}

In the evaluation or investigation practice of this mode of teaching, some notable problems concerning teaching business courses in English or bilingualism have been found as follows:

First, worries or doubts exist in learners or even teachers about the real effect or teaching quality. These doubts include: for example, teaching business courses such as Economics, Management and Law in English or bilingualism, especially in complete English, may undermine or the understanding of a specialized business skill or theory. It is argued that some business, finance or economics theories themselves are very profound and difficult to understand even in Chinese as a mother language, so it will be extremely tough to explain them clearly in English as a second language.

Second, the shortage of competent teachers who are equally good in English language and business knowledge negatively impacts the quality of this teaching mode. In some programs or classes conducting this mode of teaching, the required teachers are not competent or not ready for teaching business courses in English or bilingualism, but their school may follow the "fashion" of teaching in a hurry, or seek for the so-called approach of "education innovation" painstakingly, so they begin to teach the courses. The questionnaire survey in Guangwai indicates that the students' satisfaction level for their teachers' teaching in English or bilingualism is not high, with high satisfaction and basic satisfaction reaching less than $50 \%$. The students' complaints include: some teachers are teaching the business courses in too much Chinese, and the spoken English expression or course instruction is the main factor negatively impacting the teaching quality, etc.

Third, the teaching methodology or teaching skill of some teachers needs to be improved to reach the expected teaching effect. Some teachers are using the original foreign teaching materials which are not suitable for Chinese situation or Chinese students, for example, the thick original versions of core textbooks used in a undergraduate teaching program may be those core textbooks written for a foreign university's postgraduate program, not saying that some of the textbooks are out of date. Some teachers are not managing the lectures of the courses in a proper speed or rhythm, and they have not offered sufficient support or instruction for the students who are in difficult study.

Forth, the English language ability of some students is not fit or suitable for taking the courses taught in English or bilingualism, but they actively or passively select these programs or classes for varies of reasons, such as parents' pressure, challenging oneself or following "fashion". Although teachers are very good or best fit, the contradiction between teachers' teaching and learners' learning still exists. Some students just feel difficult in reading the texts, understanding the lectures or writing the exam papers and homework in English. So the kind of students can not reach their learning outcomes or objectives.

\section{Conclusion and Suggestions}

Teaching courses in English or bilingualism in China is commonly believed to have originated from the method of language immersion education. This mode of teaching has been promoted by China Ministry of Education as an innovative approach to higher education since 2001. This approach of teaching has been more and more popular in the Chinese universities, but there is a shortage of researches on or reflections into how to enhance the quality of this mode of teaching practice. Guangdong University of Foreign Studies (Guangwai) has taken the lead of Chinese universities in launching the various program of teaching business courses in this mode, and has accumulated some experiences for other institutions to learn as references.

In the practices of Guangwai, teaching business courses in English or bilingualism can be divided into the three main types based on the nature of degree programs, classes or courses, namely the degree programs taught in English such as the postgraduate degree program of MBA in English instruction and the undergraduate degree programs of English language, Business English and English education, the classes taught in English are actually the business-related majors taught in English, and the courses taught in this mode such as the partial courses of the non-language undergraduate or postgraduate degree programs offered by School of International Trade and Economics, School of Management, etc. The teachers with qualifications in both English language and business knowledge are normally the most suitable ones for teaching business courses in English or bilingualism. The best performance in this teaching mode mostly belongs to the teachers with BA degree in English language and MA or PhD degree in business. Business work experiences can also add additional advantages to the teachers. In addition, a majority of textbooks used are original English business textbooks imported from foreign countries, and the PPTs of the teaching materials are mostly prepared or presented in English, with only a few key business terms or theories in Chinese. In fact, over 62 percent of the investigated students recognize the mixed use of original foreign core textbooks written in English and some supplementary domestic teaching materials written in Chinese. 
Some notable problems concerning the mode of teaching have been found as follows:

worries or doubts exist in learners or even teachers about the real effect or teaching quality; the shortage of competent teachers who are equally good in English language and business knowledge negatively impacts the quality of this teaching mode; the English language ability of some students is not fit or suitable for taking the courses taught in English or bilingualism; the teaching methodology or teaching skill of some teachers needs to be improved to reach the expected teaching effect, etc. Thus, the paper puts forward the following corresponding suggestions for resolving the problems:

First, it is key to cautiously rather than blindly promote the program of teaching business courses in English or bilingualism. The purpose of this mode of teaching is to enhance the students' specialized knowledge or skill in international business communication, but not to seek for the form of teaching as a fashion, which means that the mode of teaching should be conducted on the precondition of quality control or guarantee.

Second, it is essential to develop the needed multi-skilled teachers who are good at both English language and business knowledge before launching the mode of teaching. The most competent teachers to be recruited or developed are those with a BA degree in English language and a MA or PhD degree in business as well as some overseas study or business work experience. The teachers who are degree holders of only English language should improve their business knowledge through self-study or training. Those teachers whose English, especially spoken English ability, is limited had better not be arranged to undertake this mode of teaching.

Third, it is necessary to carefully choose and use the proper textbooks or teaching materials for this mode of teaching, such as the mixed use of original core textbooks in English plus supplementary domestic teaching materials in Chinese, which are fit for Chinese learners. In addition, the courses taught with these teaching materials should be instructed or taught mostly in English with minimized Chinese explanations in order to reach the expected teaching and learning outcomes.

Finally, it is important to ensure the students are ready for taking this mode of teaching. The university should properly admit or select those students whose English level is OK or suitable for taking the courses taught in English or bilingualism, instead of pushing the admission of the students in a hurry without considering the quality of teaching. The students themselves should also be careful in choosing the kind of courses taught in English. If their English ability is not ready or not competent enough for handling the mode of teaching, they should not take it. Once they have taken it, they should work in improving their English first or do more preparation before the class.

In a word, the mode of teaching needs the enhancement of university management in terms of developing and enforcing a stricter entry standard for programs or courses, teachers, teaching materials as well as teaching methodologies. Only when these key elements are considered and prepared well can the mode of teaching reach the expected teaching performance and learning outcome.

\section{Acknowledgements}

This paper is sponsored by the 2012 Project of Postgraduate Teaching Reform (12GWYJSJG-10) sponsored by Guangdong University of Foreign Studies and the 2012 Project of Higher Education Teaching Quality and Reform (222-GK120063) sponsored by Guangdong Provincial Department of Education.

\section{References}

Baker, C. (1993). Foundations of Bilingual Education and Bilingualism. Clevedon: Multilingual Matters.

Cai, Y. (2001). Some Thinking about Teaching in English. Journal of Guangdong University of Foreign Studies.

Cai, Y. (2005). Research on the design and implementation of English immersion education by taking the programme of international business management (taught in English) as an example. International Economics and trade Research.

China Ministry of Education. (2001). [2001] No.4 Official Document concerning Education Guidelines of Enhancing College Undergraduate Teaching Work. http://xpgb.swu.edu.cn/article/2007/0624/article _208.html

Dai, X. Y. (2003). Basic Factor Analysis of Teaching Marketing in Bilingualism Based on the Case of Beijing Normal University's Practices. China Higher Education.

Johnson, R. K., \& Swain, M. (1997). Immersion Education: International Perspectives. Cambridge University Press. 
Qiang, H. Y., \& Siegel, L. S. (2012). Introduction of English Immersion in China: A Transplant with Modifications. International Education, 41(2).

Qing, S. (2007). Rethinking about the mode of English immersion education. Science Information.

Ouyang, A. P. (2011). Research on teaching strategies for international special talents based on the example of Beijing University of Commerce's CAP education. Modern Higher Education.

Wang, X. (2012). A comparative study and analysis of English immersion teaching modes in higher education institutions between Hong Kong and Mainland. Business.

Wikipedia, the free encyclopedia. (2013)._Language immersion. http://en.wikipedia.org/wiki/Language_immersion

Zhou, R. Q. (2013). The application of the teaching method of case studies in teaching the course of international trade practices in English. Education for Chinese After-school (Theory).

Zhu, W. Z. (2005). Investigation and Analysis of the English Immersion Education. International Economics and Trade Research.

Zhu, W. Z. (2011). Business English Teaching and Research. World Publication Corporation.

\section{Copyrights}

Copyright for this article is retained by the author(s), with first publication rights granted to the journal.

This is an open-access article distributed under the terms and conditions of the Creative Commons Attribution license (http://creativecommons.org/licenses/by/3.0/). 